\title{
Sustainability awareness in organizations through gamification and serious games: a systematic mapping
}

\author{
Giulia Wally Scurati ${ }^{1}$, Francesco Ferrise ${ }^{1}$, Marco Bertoni ${ }^{2}$ \\ ${ }^{1}$ Politecnico di Milano \\ giuliawally.scurati@polimi.it \\ fancesco.ferrise@polimi.it \\ ${ }^{2}$ Blekinge Institute of Technology \\ marco.bertoni@bth.se
}

\begin{abstract}
The transition towards more sustainable practices is one of the main challenges that companies and organizations are currently facing. The use of serious games and gamification has shown to be effective in creating awareness and support learning in many contexts, including sustainability education of practitioners and future ones. We performed a systematic mapping of the use of games on sustainability for companies and organizations. The results show current trends and voids in research concerning a series of categories and provide insights on possible future directions in this area.
\end{abstract}

Keywords: sustainability, gamification, human behaviour, sustainable design

\section{Introduction}

The global concern for the environmental, social and economic issues deriving from an unconscious growth and consumption behaviours is raising, and their consequences appear to be increasingly more imminent and serious. The need for a rapid and substantial transition towards more sustainable societies and economies is stressed by the United Nation's Sustainable Development Goals (Griggs et al., 2013). These, in turn, foster a wave of change at different levels in the organization, and in particular, in the way products and services are designed and delivered, including resources management, planning of supply and production, and cooperation of multiple stakeholders. Among the many tools to support this transformation, gamification and serious games hold serious potential for many reasons. Gamification, that is the use of game elements in non-gaming contexts (Deterting et al., 2011) has already shown to be effective as a learning tool for education in many domains (Ravyse et al., 2017), as well as a training tool professional and industrial fields (Agogué, Levillain, and Hooge, 2015; Uskov and Sekar, 2014). Serious games have also been widely popularised to educate the general public on sustainability-related issues (Johnson et al., 2017), motivating a change of behaviour and creating awareness. A relevant example is the board game for children that has been 
designed to specifically address the topic of sustainable development goals (https://gogoals.org/it/). Moreover, there have been several attempts to teach, support and integrate sustainability strategies in companies and organizations, educating inexperienced and expert professionals, as well as future ones, through gaming experiences (Stanitsas, Kirytopoulos, and Vareilles, 2019; Madani, Pierce, and Mirchi, 2017). Serious games excel in the task of simplifying complex situations and systems, so to support decision making and the development of both hard and soft skills (Riedel and Hauge, 2011). This property makes them stand out in the quest for methods and tools able to trigger discussion and knowledge sharing about sustainability-related issues in modern cross-disciplinary design teams. In particular, in the field of engineering design, early-stage decision making requires the participation of a range of disciplines, each one contributing with their specific knowledge - about the way a product is manufactured, operated, maintained, upgraded, dismissed or recycled. Across this range of stakeholders, the application of serious games for sustainable awareness is observed to be in its infancy and very scattered.

The main aim of this research is to analyse the extent to which gamification and serious games are used today in organizations to raise awareness on sustainability and environmental concerns. Hence, we collate, describe, and catalogue available evidence concerning the use of sustainability-related gamification approaches at a strategical, tactical and operational level.

Rather than merely focusing on the discipline of engineering design, this paper undertakes a broad, open-minded mapping - across industrial roles and fields - spotlighting which different categories of games exist, their use according to their audience, their target users (students vs professionals in enterprises) and learning objectives. By mapping existing approaches, the research identifies knowledge clusters, gaps, and extracts main recommendations for the further definition of ad-hoc game requirements. This knowledge is, in turn, important to elaborate on the most effective strategies, techniques and mechanisms for the development of a gaming approach and guidelines targeting the early phases of concept design.

\section{Systematic mapping study design}

This paper does not attempt answering to a specific question as done in systematic reviews. Rather, it wants to direct future research with regards to how serious games can contribute to the discipline of design. This makes it difficult to decide what studies are relevant for a systematic review, e.g., to define specific keywords and inclusion/exclusion criteria. For this reason, the authors borrowed the systematic mapping technique from social sciences research to address a broad subject. Hence, in a similar way as what proposed by Dicheva et al. (2015), the study aims to provide a comprehensive map of game features, contexts of application, and trends in the area. It is worth noticing that the systematic mapping process is designed to be as rigorous, objective and transparent as the systematic review process. For this reason, prior to the review the authors prepared a systematic mapping protocol describing the methods to be used, as well as the background and scope of the study. The evidence from a systematic mapping study is then catalogued in the form of a database (e.g., see James, Randall, and Haddaway, 2016). In here, each study is categorised using content-based (e.g. study setting, design, intervention/s, population/s) and publication-based meta-data (e.g. author, title, year, peer-review journal, conference proceeding). These are used to assess the quantity and nature of research in a particular area, e.g., accounting for the number of articles published in journals, the number of studies from each country of origin; the type and number of interventions, the population types and more. In this study, the systematic mapping study was performed on two databases - Web of Science (WoS) and Scopus - through a search query featuring the keywords listed in Table 1. The studies were initially filtered on the basis of their title, abstract and keywords. In order to reduce the number of entries associated with the keyword 'game*', the 
authors decided to combine it with the 'education' and 'training' keywords. To further focus the search in the sustainability domain, the authors made use of several keywords that address related challenges and phenomena (e.g. climate change) and that are linked to typical fields, strategies and practices (e.g. energy, LCA). Finally, to limit the investigation to the professional context, we used a set of keywords connected to selected disciplines (e.g. engineering, management) and synonyms for 'organizations' (e.g. company, enterprise).

Table 1 Search words to identify the use of games, the specific topics related to sustainability and the specific context of companies/organizations

\begin{tabular}{|l|l|l|}
\hline $\begin{array}{l}\text { Search words to identify the } \\
\text { use of games/gamification }\end{array}$ & $\begin{array}{l}\text { Search words to identify the } \\
\text { sustainability related topic }\end{array}$ & $\begin{array}{l}\text { Search words to identify the } \\
\text { companies/organizations } \\
\text { contexts }\end{array}$ \\
\hline Serious game*/gaming & Sustainab* & Compan* \\
\hline Gamification & Environmental & Corporate* \\
\hline Game*/gaming + training & Risk & Design \\
\hline Game*/gaming + education & Material* & Engineering \\
\hline & Life Cycle Assessment/ LCA & Enterprise* \\
\hline & Climate change & Industrial \\
\hline & Carbon footprint & Management \\
\hline & Energy & Manufacturing \\
\hline & Circular Economy & Marketing \\
\hline & Resource* & Organization* \\
\hline & Waste & Product development \\
\hline
\end{tabular}

Looking at publication-related criteria, the study was limited to articles and reviews published after 2000. Eventually, the search query rendered 251 publications on WoS and 443 publications on the Scopus database. These results were then filtered by iteratively applying the following content-related inclusion and exclusion criteria to title, abstract and full text:

- The work regards the use of serious games for companies/organizations to achieve sustainability targets;

- The work targets at practitioners/stakeholders or future ones (students);

- The aim of the game is related to specific strategic/management/engineering/production tasks and decisions;

- The work targets only at the general public/consumers (e.g. clients, users);

- The work only targets at practitioners' awareness and civic behaviour, regarding tasks that are not related to the company business (e.g. green mobility for employees);

The filtering process rendered 65 publications, among which 16 were only found on WoS, 37 only on Scopus, and 12 were found in both databases. Figure 1 shows the distribution of these contributions per year of publication. Noticeably, that there has been a rapid - even though not linear - increase in the interest in this research area in the past years.

\section{Categorization criteria and mapping}

Research questions when categorizing the findings include: for which kind of problem and in which area serious games and gamification are used to reach sustainability-related goals in the industry? How are they applied in educational and professional contexts? What types of games are used? 


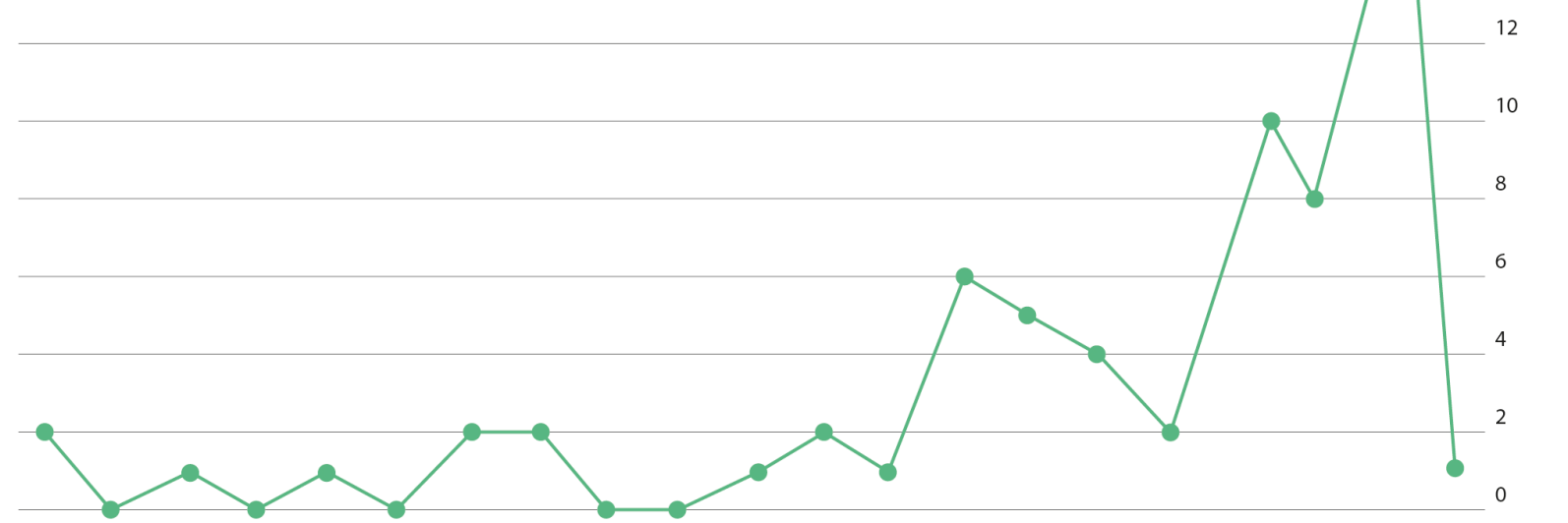

200020012002200320042005200620072008200920102011201220132014201520162017201820192020 Year

Figure 1 Documents published per year.

Studies were mapped according to the kind of game and topics of interest, since they are the most relevant categories to answer the questions stated above. Considering the kind of game, their position on the map (Figure 2) can be explained as follow. Role-play and board games present important social dimensions since they imply perspective change and/or interaction with other players. On the other hand, metaphors and gamified learning are used to make concepts more understandable and engaging for players, without a specific need for cooperation: they rather address individuals learning process and performances. Simulation and gamified practice may be more social or individual-oriented depending on the specific tasks and aims. Reviews often discuss various kind of games and topics. The bubble colour indicates the percentage of studies targeting at students (orange), professionals (purple) or both (green). Considering the kind of game related to the target user, it is not surprising that gamified learning is mainly applied for students, while the gamified practice is used for professionals. Simulations, as well as board games, appear to be diffused in both the contexts, while role-play is more common for professionals or mixed users. Looking at board games, those targeting at students seem to be slightly more diffused for some specific audiences as LCA, business/management, circular economy, rather than for multidisciplinary and collaborative tasks (e.g. policy making, resource management) or fields related to values (corporate responsibility, professional ethics).

In the following, we explain the categories shown in the map. Moreover, we identify a larger set of aspects to investigate, and a number of options for each category. Considering some categorization criteria, as the target sustainability issues and audiences, each study could refer to more than one option.

\subsection{Audiences}

The audiences' axis identifies the academic or professional field or even a specific approach as a mean to answer to the sustainability needs described in the Section 3.3. These range from general areas (e.g. Business/management) to methods and tasks (e.g. lean manufacturing, LCA). In particular, resource management is the most diffused audience with 12 studies $(18.5 \%)$ is a wide audience, being the main strategy to achieve sustainability goals in many fields and including a range of measures and methods. It is followed by lean manufacturing, 
that is in contrast a narrower audience; however, there is a high interest (9 studies, 13.5\%) probably due to the fact that it is also strictly related to cost efficiency.

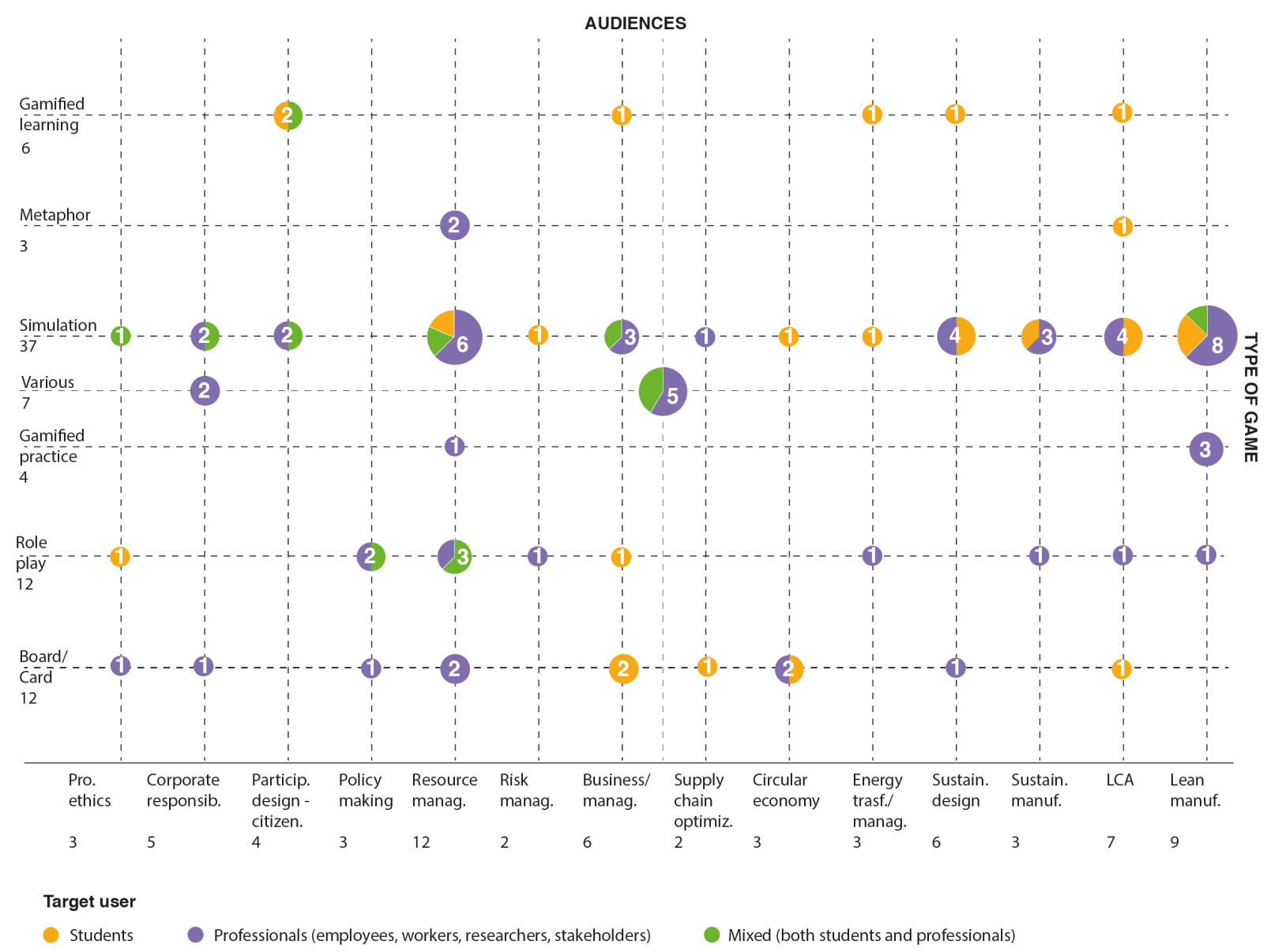

Figure 2 Distribution and mapping of work for audiences, type of game and target user.

LCA ( 7 studies, $10.8 \%$ ) has a strong tradition in the design field as a method to evaluate a product impact during its development. $6(9.2 \%)$ studies can be found in the area of business/management, and the same number can be found considering sustainable design. 4 (6.1\%) studies are concerning participatory design/citizenship. $3(4.6 \%)$ studies are regarding professional ethics, as well as policy-making, circular economy, energy transformation and management and sustainable manufacturing. Finally, $2(3 \%)$ studies are about risk management, as for supply chain optimization.

\subsection{Game type}

The mapping is based on six main categories of gamification techniques for education, training and performance improvement, that are defined as the following:

- Simulation: imagining (or reproducing) and analysing a real situation (e.g. product, building, production line performance depending on design/management choices);

- Metaphor: differs from the simulation as it is not the representation of a real situation for the users, but it shares some mechanisms and logic with a real one;

- Role-play: similar to a simulation, but users have to act the part of a specific role;

- Gamified learning: gamifying learning activity, how the learning material and information are presented and tested (e.g. using quiz); 
- Gamified practice: gamification is embedded into habitual working or practical learning activities/projects (e.g. scores are assigned to tasks, use of tools is tracked);

- Board/cards game: resembles a traditional table game (reproducing a simulation or metaphor or learning situation);

Simulation games are increasing practical skills and procedural knowledge, offering an opportunity for students and inexperienced employees to experiment a possible real situation, understanding better their future role (Cohen, Niemeyer, and Callaway, 2017; Ayer, Messner, and Anumba., 2016). However, simulation games can also be used by practitioners to test and evaluate new methodologies or strategies (Celio, Andriatsitohaina, and Zaehringer, 2019; Hardeveld et al., 2019). Many studies (39 studies, 60\%) fall into the category of simulations, as the term simulation can indicate a variety of approaches. Role-play games support the understanding of multiple situations and phenomena related to a certain decision or practice, including the point of view and all the parts involved and different stakeholders (Schrier, 2015). Board/card games reproduce and take advantage of traditional games, they are used to raise engagement and discussion, as they are typically played in a social context (Whalen and Peck, 2014). Board games and role-play games are specifically useful for collaborative and negotiation contexts as they offer opportunities to discuss and experiment others role, facilitating a change of perspective. Metaphors allow a better understanding of complex phenomena, creating a link with a simpler and more familiar one, also representing an optimal tool for inexperienced users or during activities requiring a high mental workload.

An example is the use of a garden to represent the energy use by employees in the office (Oppong-Tawiah et al. 2020). Metaphor is not widespread for this kind of applications, while it is a common strategy in other contexts where users' engagement and emotional involvement are more important than gaining specific skills or knowledge. Examples are serious games dedicated to health and exergames, (Lin et al., 2006; Byrne et al., 2012), the use of metaphor is also used to represent household resource consumption (Tiefenbeck et al., 2019).

Gamified learning and practice refer to the gamification of usual activities and aim at enhancing learning or productivity performances by engaging and motivating users.

\subsection{Target sustainability issue/need}

Many works refer to sustainable development general targets, often relating to the concept of Triple Bottom Line (TBL), including social and economic dimensions along with the environmental one. In fact, as shown in Figure 3, sustainable development is the most mentioned issue, with 31 studies $(47.7 \%)$. Some of them aim at containing the temperature raise, causing climate change ( 4 studies, $6.1 \%$ ) and the consequent adaptation of businesses and practices. Several contributions describe serious games aiming at raising awareness on how to reduce resource exploitation ( 8 studies, $12.3 \%$ ) waste production (6 studies, $9.2 \%$ ), and energy consumption (e.g., through renewable energy) (7 studies, 10.8\%). Other works refer to more specific issues and needs: for instance, the use of territorial resources, lands and related natural risks (4 studies, 6.1\%), water scarcity ( 4 studies, $6.1 \%$ ), material criticality ( 2 studies, $3 \%$ ) and ecosystems conservation ( 1 study, $1.5 \%$ ).

\subsection{Sector}

As shown in Figure 4, generic studies are widespread (30 studies, 46.1\%) since many of them are for research purposes or education, hence there is not a specific sector. The environmental/natural resources field is also diffused (9 studies, 13.8\%) because of the rising concern for natural phenomena linked to climate change, resources scarcity and simultaneous increases of demand, enhancing the risk of crisis and conflicts among the population. 


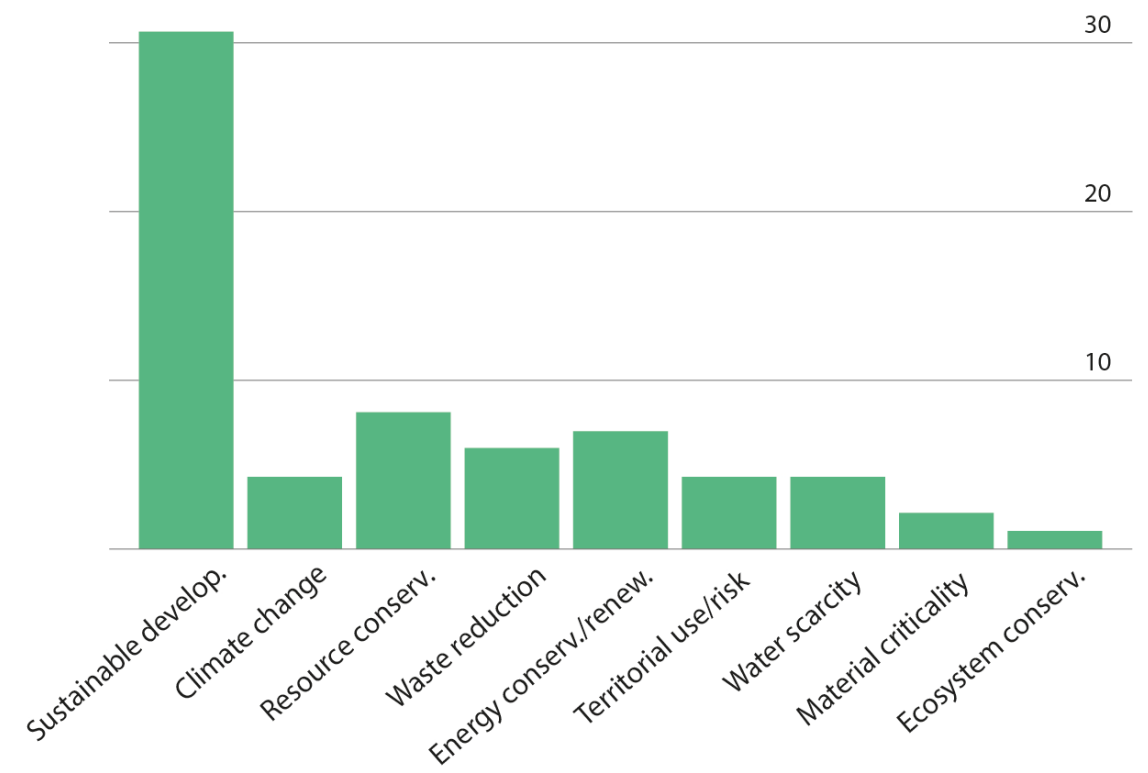

Figure 2 Work distribution by targeted environmental issue

Another sector counting a discrete number of studies $(8,12.3 \%)$ is the one of construction/architecture. The concept of zero energy buildings, is indeed one of the strategies implemented by the EU to have a significant reduction of energy consumption (D'Agostino et al. 2016). 2 studies (3\%) are concerning urban planning and development, $2(3 \%)$ are in the automotive field, $2(3 \%)$ are in civil engineering/infrastructures, 1 in automation technologies $(1.5 \%), 1$ considering tourism $(1.5 \%), 1$ regarding fishery $(1.5 \%), 1$ about product/service design (1.5\%).

\subsection{Analog versus digital games}

30

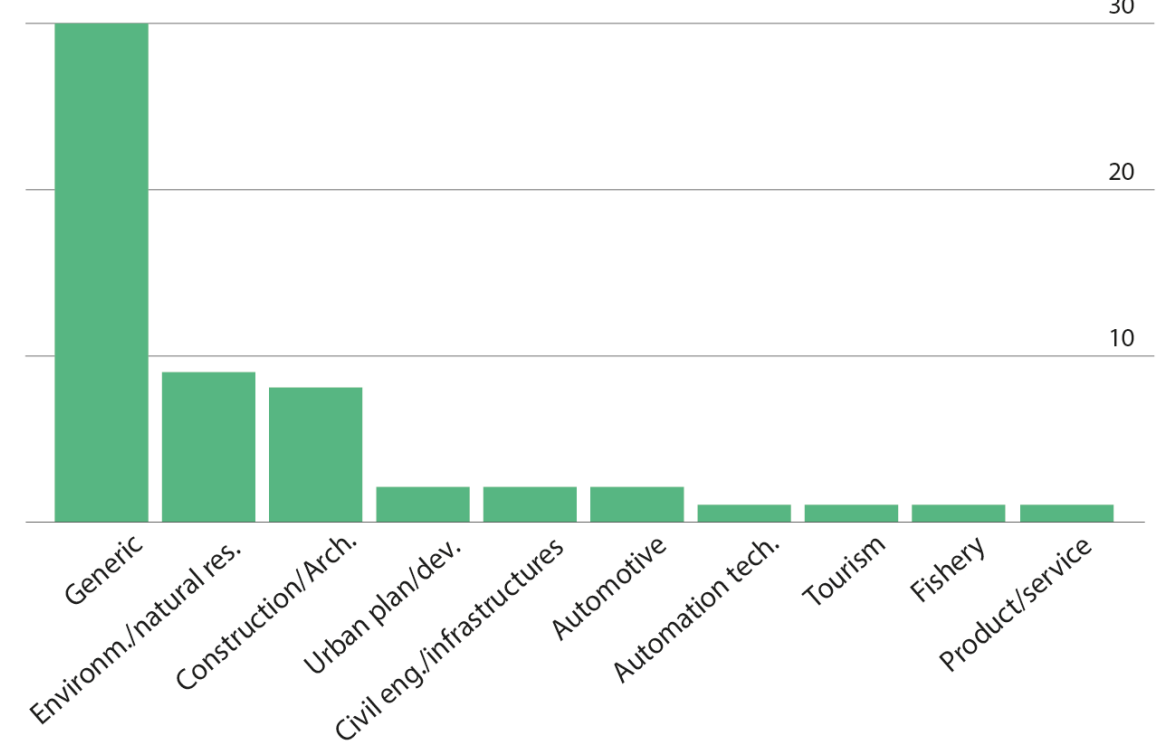

Figure 4 Work distribution by sector.

Among the examined studies, 20 describe analogue games, while 45 digital games (including 1 AR game). The prevalence of digital games is probably due to the fact that real-world settings are often more demanding from the economic and organizational point of view, while digital games are more convenient. Advantages include the possibility of rapidly simulating and getting feedback, using models and collect data. An example of a digital game is proposed by 
Oppong-Tawiah et al. (2020), presenting a mobile application to monitor and provide feedback to energy consumption in the office. Interactivity is one of the main advantages of digital games, (van Hardeveld et al. 2019). Digitalizing learning, training and support material is also a trend in Industry 4.0 (Tvenge and Martinsen, 2018; Scurati et al., 2018).

However, games that are implemented in a physical environment sometimes allow to recreate more credible training situations in an industrial context. An example is provided by the instructional factory proposed by De Vin and Jacobsson (2017), which is composed of workstations mock-ups used to perform simulations for processing, batch processing and assembly. Moreover, analogue games enable more interaction among players when the development of interpersonal skills is required. One example is what proposed by Koens et al. (2019), who use a board game to stimulate reflective conversations among stakeholders to improve governance practice for sustainable tourism.

\section{Discussion and conclusion}

This paper has explored the variety and distribution of work regarding the use of gamification for industrial/enterprise sectors to support sustainable development, education and training. The growing popularity of gamification to foster sustainability awareness in a professional context - and specifically, design engineering and management - is unquestionable.

The analysis reveals that simulations are one of the most widespread strategies for gamification, as demonstrated by the number and variety of studies falling into this definition. All board/card games take place in an analogue setting, while simulations and role-play games can be both analogue and digital. In particular, simulations include a variety of games and approaches. Both analogue and digital simulation can involve multiple users (e.g. simulating a co-design activity in a real environment, or a resource management process with more stakeholders in a virtual one) or single users (e.g. simulating an assembly task in a real setting or an LCA in a virtual model). For the possibility to use models and make predictions, digital simulations represent almost the total amount of games in fields as environmental/natural resources and for resource management tasks, taking advantage from the visualization of possible outcomes, especially when involving negotiation among different stakeholders. On the other hand, there is a void of games for other typologies. In particular, the use of metaphor is rare, because they are more suitable to create awareness and emotional involvement than for gaining skills. However, they could be used for specific purposes, for instance, to capture and represent customer emotions and opinions considering the use of sustainable strategies. Also, gamified practice, meaning the gamification of regular working activities, might be hard to implement.

Resource management, LCA and lean manufacturing are the most diffused audiences. The first is the most cited approach to reduce environmental and social impact and can refer to a variety of contexts, while LCA is typical for product development and lean manufacturing for production. Regarding target users, games seem to be evenly distributed among students and practitioners, with some studies targeting at both. However, despite the high percentage of games dedicated to practitioners, a vast majority does not refer to a specific sector, as specified in Section 3.3. Even though this can be good in an educational context, it may also be an obstacle to the use of serious games in the industry, since they should be context related to be fully effective (Riedel and Hauge 2011). Moreover, despite it is not the aim of this work, this could also make it problematic to assess the possible impact of the use of gamification for sustainable development in the industrial sector, and to which extent it can contribute to a sustainability transition in design, production and society. Considering the current analysis, it is possible to provide serious games designers for sustainability in the industry with the following suggestions, to decide the kind of game to design: 
- In collective contexts, card/board games and role-play games can support collaboration, negotiation and dialogue;

- In collective contexts, when possible, an analogue setting could be beneficial, as it is easier to create a discussion;

- Digital games are ideal when interactivity and feedback to players' actions or choices are fundamental, as for presenting/testing solutions or address specific behaviours;

- For individual learning and awareness, the use of metaphor could be explored;

- To enhance practical skills, simulations and gamified practice can be used to replicate or facilitate real situations;

- Gamified learning can be suitable to provide knowledge, especially for students;

As we can observe in Figure 1, this kind of analysis can be premature; however, we can state that there is a growing trend in the use of similar applications in research and that it is likely to grow further. Future directions may include a focus on specific sectors and related issues, including the implementation of industrial case studies. In fact, this is fundamental to assess the impact of gamification on professionals' attitude and behaviour, as well as on working activities, including collaborative tasks, design and negotiation processes. This would make it possible to provide more precise and solid suggestions to game developers, setting specific requirements. Moreover, it would be interesting to compare the impact in professional and educational fields and the results that can be obtained on students, employees and practitioners at various levels in organizations. This would also help to draw further guidelines for the development of this kind of games and gamification strategies in different contexts and for different target users and objectives.

\section{Citations and References}

Agogué, M., Levillain, K., \& Hooge, S. (2015). Gamification of creativity: exploring the usefulness of serious games for ideation. Creativity and Innovation Management, 24(3), 415-429.

Ayer, S. K., Messner, J. I., \& Anumba, C. J. (2016). Augmented reality gaming in sustainable design education. Journal of Architectural Engineering, 22(1), 04015012.

Byrne, S., Gay, G., Pollack, J. P., Gonzales, A., Retelny, D., Lee, T., \& Wansink, B. (2012). Caring for mobile phone-based virtual pets can influence youth eating behaviours. Journal of Children and Media, 6(1), 83-99.

Celio, E., Andriatsitohaina, R. N. N., \& Zaehringer, J. G. (2019). A serious game to parameterize Bayesian networks: Validation in a case study in northeastern Madagascar. Environmental modelling \& software, 122, 104525.

Cohen, M. A., Niemeyer, G. O., \& Callaway, D. S. (2016). Griddle: Video gaming for power system education. IEEE Transactions on Power Systems, 32(4), 3069-3077.

D’Agostino, D., Zangheri, P., Cuniberti, B., Paci, D., \& Bertoldi, P. (2016). Synthesis report on the national plans for nearly zero energy buildings (NZEBs). Joint Research Center (JRC) publications.

De Vin, L.J. \& Jacobsson, L. (2017) Karlstad lean factory: an instructional factory for gamebased lean manufacturing training. Production and manufacturing research-An open access journal 5(1):268-283.

Deterding, S., Dixon, D., Khaled, R., \& Nacke, L. (2011, September). From game design elements to gamefulness: defining" gamification". In Proceedings of the 15th international academic MindTrek conference: Envisioning future media environments (pp. 9-15). 
Dicheva, D., Dichev, C., Agre, G., \& Angelova, G. (2015). Gamification in education: A systematic mapping study. Journal of Educational Technology \& Society, 18(3).

Griggs, D., Stafford-Smith, M., Gaffney, O., Rockström, J., Öhman, M.C., Shyamsundar, P., Steffen, W., Glaser, G., Kanie, N. and Noble, I. (2013). Policy: Sustainable development goals for people and planet. Nature, 495(7441), 305.

van Hardeveld, H. A., Driessen, P. P. J., Schot, P. P., \& Wassen, M. J. (2019). How interactive simulations can improve the support of environmental management-lessons from the Dutch peatlands. Environmental Modelling \& Software, 119, 135-146.

James, K. L., Randall, N. P., \& Haddaway, N. R. (2016). A methodology for systematic mapping in environmental sciences. Environmental evidence, 5(1), 7.

Johnson, D., Horton, E., Mulcahy, R., \& Foth, M. (2017). Gamification and serious games within the domain of domestic energy consumption: A systematic review. Renewable and Sustainable Energy Reviews, 73, 249-264.

Koens, K., Melissen, F. , Mayer, I., \& Aall, C. (2019). The smart city hospitality framework: Creating a foundation for collaborative reflections on over-tourism that support destination design. Journal of Destination Marketing and Management.

Lin, J. J., Mamykina, L., Lindtner, S., Delajoux, G., \& Strub, H. B. (2006, September). Fish'n'Steps: Encouraging physical activity with an interactive computer game. In International conference on ubiquitous computing (pp. 261-278). Springer, Berlin, Heidelberg.

Madani, K., Pierce, T. W., \& Mirchi, A. (2017). Serious games on environmental management. Sustainable Cities and Society, 29, 1-11.

Oppong-Tawiah, D., Webster, J., Staples, S., Cameron, A. F., de Guinea, A. O., \& Hung, T. Y. (2020). Developing a gamified mobile application to encourage sustainable energy use in the office. Journal of Business Research, 106, 388-405.

Ravyse, W. S., Blignaut, A. S., Leendertz, V., \& Woolner, A. (2017). Success factors for serious games to enhance learning: a systematic review. Virtual Reality, 21(1), 31-58.

Riedel, J. C., \& Hauge, J. B. (2011, June). State of the art of serious games for business and industry. In 2011 17th International Conference on Concurrent Enterprising (pp. 1-8). IEEE.

Schrier, K. (2015). Ethical thinking and sustainability in role-play participants: A preliminary study. Simulation \& Gaming, 46(6), 673-696.

Scurati, G. W., Gattullo, M., Fiorentino, M., Ferrise, F., Bordegoni, M., \& Uva, A. E. (2018). Converting maintenance actions into standard symbols for Augmented Reality applications in Industry 4.0. Computers in Industry, 98, 68-79.

Stanitsas, M., Kirytopoulos, K., \& Vareilles, E. (2019). Facilitating sustainability transition through serious games: A systematic literature review. Journal of cleaner production, 208, 924-936.

Tiefenbeck, V., Wörner, A., Schöb, S., Fleisch, E., \& Staake, T. (2019). Real-time feedback promotes energy conservation in the absence of volunteer selection bias and monetary incentives. Nature Energy, 4(1), 35-41.

Tvenge, N., \& Martinsen, K. (2018). Integration of digital learning in industry 4.0. Procedia manufacturing, 23, 261-266.

Uskov, A., \& Sekar, B. (2014, June). Serious games, gamification and game engines to support framework activities in engineering: Case studies, analysis, classifications and outcomes. In IEEE international conference on electro/information technology (pp. 618623). IEEE.

Whalen, K., \& Peck, D. (2014). In the Loop-Sustainable, Circular Product Design and Critical Materials. International Journal of Automation Technology, 8(5), 664-676. 